\title{
G scistam \\ Contribution In Determining The Fatigue Endurance of Slide Diamond Burnishing AISI52100 Steel Components
}

\section{Ouahiba Taamallah}

Research Laboratory of Advanced Technology in Mechanical Production (LRATPM), Mechanical Engineering Department Badji Mokhtar-Annaba University, P.O. Box 12, 23000 Annaba, Algeria Hamid Hamadache

Research Laboratory of Advanced Technology in Mechanical Production (LRATPM), Mechanical Engineering Department Badji Mokhtar-Annaba University, P.O. Box 12, 23000 Annaba, Algeria Abdelaziz Amirat ( $\nabla$ abdelaziz.amirat@univ-annaba.dz )

Research Laboratory of Advanced Technology in Mechanical Production (LRATPM), Mechanical Engineering Department Badji Mokhtar-Annaba University, P.O. Box 12, 23000 Annaba, Algeria

\section{Ouzine Boussaid}

Laboratoire de Recherche en Risque Industriels Contrôle et Sureté (L2RCS), Department of Mechanical Engineering, Faculty of Engineering Sciences, Badji Mokhtar-Annaba University, BP 12, Annaba 23000, Algeria.

\section{Research Article}

Keywords: AISI 52100 Steel, slide diamond burnishing, Wöhler, fatigue endurance

Posted Date: July 30th, 2021

DOI: https://doi.org/10.21203/rs.3.rs-734340/v1

License: (c) (i) This work is licensed under a Creative Commons Attribution 4.0 International License. Read Full License 


\section{Abstract}

The present paper is an investigation on the effect of slide diamond burnishing on the fatigue endurance of a component made of AISI52100 steel. Burnishing operation has been performed on cylindrical specimens using optimal parameters statistically selected such as burnishing force, burnishing feed and number of tool passes. Bending fatigue tests in air at $\mathrm{R}=-1$ and $\mathrm{S}-\mathrm{N}$ curves have been plotted by incrementing the applied stress from a maximum stress level of about $66 \%$ of the ultimate tensile stress to a stress value below which fatigue does not occur. Results show that slide diamond burnishing has increased the fatigue resistance comparing to unburnished specimens. The fatigue endurance is respectively $222 \mathrm{MPa}$ and $190 \mathrm{MPa}$. At high stress levels, the fatigue resistance improvement is clearly observed and the fatigue trends are in good agreement with those reported in literature. However, the present results are slightly lower and that is attributed to the shoulder fillet value of the specimen. For small fillet radius, fatigue resistance is lowered.

\section{Introduction}

Nowadays, ball burnishing surface finish process is considered as one of the best alternative to increase fatigue lifespan of engineering components [1,2]. Recent research works have demonstrated its effectiveness through three main parameters, decreasing surface roughness, increasing surface hardness and particularly generating surface compressive residual stresses [3, 4]. Usually, the burnishing process consists in sliding carbide or diamond tool in the form of roller or ball surface by applying pressure sufficient to create surface plastic deformation improving the surface integrity of the component. However, the performance of the burnishing process depends on the material and the geometry of the part, and also on the material and geometry of the burnishing tool together with the conditions of burnishing process that should be carefully selected $[5,6]$.

Recently Maximov et al [7] have devoted a review paper on state-of-the-art, achievements and perspectives of the slide burnishing of metal components. They have concluded that the majority of slide burnishing studies are focused on the study of surface integrity, where the attention is focused mostly on the roughness and microhardness, whereas, significantly less attention is paid to wear resistance and fatigue strength.

For instance, Rodríguez et al [8]_in their investigation on surface improvement of shafts by the deep ballburnishing technique have shown that ball-burnishing performs both physical and mechanical properties of turned parts by improving surface quality, increasing the hardness of the workpiece and introducing compressive residual stresses which are favorable for increasing the fatigue life of the piece and improve the wear resistance of the component. Moreover, they have pointed out that the most influencing parameter in the burnishing pressure which should be carefully selected rather than the burnishing speed and feed rate have little effect therefore maximum values should be used as the processing time can be significantly reduced. 
Meanwhile, the interest to fatigue resistance is related to the beneficial effect of ball burnishing in generating compressive residual stress at the surface layers of a component $[9,10]$. Amador et al [11] have carried investigation on ball burnishing effect on deep residual stress on AISI 1038 steel. Using hole drilling technique, they have shown that ball burnishing has proved to introduce relevant residual stress up to $0.6 \mathrm{~mm}$ depth which is very relevant in using the process as an industrial finishing process to improve the surface finish parts subjected to fatigue working regimes.

One the research work that is coherent with the effect ball burnishing on fatigue resistant is that reported by Sadeler et al [12]. They have investigated the influence of ball burnishing on fatigue behaviour of AISI 1045 steel and have demonstrated that the fatigue limit and fatigue life are improved by the burnishing finish process. R. Avilés et al [13] have studied the Influence of low-plasticity ball burnishing on the highcycle fatigue strength of medium carbon AISI 1045 steel. .Throughout the investigation, they have provided experimental data and analyses of the surface roughness, fractography, in-depth residual stresses, and cyclic relaxation effect and have shown that the low-plasticity ball burnishing operation resulted in low surface roughness and significant improvement in fatigue strength

However the applied pressure should be sufficient to create residual deep compressive residual stress on the surface layers of the components. But in revolution parts, the fillet on cylinder shoulders is likely to be sensitive to crack initiation leading to fatigue failure. Travieso-Rodríguez et al [14] in their investigation on hardening effect and fatigue behaviour enhancement through ball burnishing on AISI 1038 steel, have presented a comprehensive study of the effects of ball burnishing on the low cycle fatigue endurance of cylindrical specimens subjected to alternative bending stress and evaluated the beneficial impact of the process on the general fatigue behaviour of AISI 1038 steel. Through five different force-number of passes. They proposed the most favourable results with respect to microhardness increase and fatigue lifespan. However, they have not presented the fatigue endurance and the effect of the shoulder fillet.

Therefore, the present work aims to produce better comprehension of the effect of slide diamond burnishing over a large span of testing cycles and the change in shoulder fillets. The contribution of the present work then consists in determining the effect of slide diamond burnishing on the fatigue endurance of a component made of AISI52100 steel. S-N curve are carried out on cylindrical specimens for untreated and ball burnished specimens. The applied pressure and slide diamond burnishing regimes are extrapolated from statistical experimental data. Results are compared to literature data.

\section{Experimental Approach}

\subsection{Material and specimen preparation}

AISI 52100 high strength low alloy steel furnished by the Maghrebian Manufacturing Workshop of the steel complex of El-Hadjar, in Algeria is used. The chemical composition and the main material properties are given respectively in Tables 1 and 2. $\sigma_{\mathrm{ut}}, \sigma_{\mathrm{y}} \sigma_{\mathrm{yh}} \sigma_{\mathrm{yl}}$ and e are respectively, the ultimate stress, the yield stress, the Upper yield stress, the lower yield stress and the elongation. 
Table. 1 Chemical composition of AISI 52100 steel in weight percent

\begin{tabular}{llllllllll}
$\mathrm{C} \%$ & $\mathrm{Mn}$ & $\mathrm{Si}$ & $\mathrm{P}$ & $\mathrm{S}$ & $\mathrm{Cu}$ & $\mathrm{Al}$ & $\mathrm{Ni}$ & $\mathrm{Cr}$ & $\mathrm{Mo}$ \\
\hline 0,95 & 0,32 & 0,24 & 0,009 & 0,022 & 0,087 & 0,032 & 0,104 & 1,395 & 0,024
\end{tabular}

Table.2 Specific mechanical properties of AISI 52100 steel.

\begin{tabular}{ccc} 
& $\mathrm{M}$ & SDB \\
\hline$\sigma_{\mathrm{e} 0,2} \mathrm{MPa}$ & 448,6 & 456,99 \\
\hline$\sigma_{\mathrm{yh}} \mathrm{MPa}$ & 450,15 & 458,55 \\
\hline$\sigma_{\mathrm{yl}} \mathrm{MPa}$ & 447,42 & 452,44 \\
\hline$\sigma_{\mathrm{ut}} \mathrm{MPa}$ & 701,2 & 722,85 \\
\hline $\mathrm{e} \%$ & 21.67 & 27,15
\end{tabular}

Fatigue specimens, are prepared from a parent bar of $400 \mathrm{~mm}$ diameter according to the specification given in the operating instruction of the fatigue machine GUNT WP 140.01

Two series of specimen (as machined and slide diamond burnished) have been prepared following the procedure described in Fig. 1.

\subsection{Slide diamond burnishing process}

In order to investigate the effect of mechanical surface treatment, a series of fatigue specimens have been subjected to slide diamond burnishing on a 16k20 lathe, Fig. 2. A purpose made diamond burnisher has been designed to achieve the burnishing operation (Details of the burnishing tool is given in literature [15]. The procedure of slide diamond burnishing operation is illustrated in Fig. 3. Burnishing is completed under SAE90 oil abundant lubricant. The burnishing parameters have been selected through a $L_{27}$ Taguchi plan [16].

\subsection{Roughness measurement :}

Roughness measurements have been carried out on as-machined specimens and on burnished specimens using Mitutoyo model SJ-301. For each specimen, three measurements of Ra are made along the specimen diameter at three angles of 0,120 and $240^{\circ}$.

\subsection{Microhardness measurement}

Microhardness have been measured using Matzuzawa model MXT70 indenter under a load of $3 \mathrm{kgf}$. Two type of measurements have been conducted. The first type concerned the microhardness along the external diameter. The second type permitted to identify the microhardness profile on the external layer of the cross section of the specimen through incremental radial distance of $0.025 \mathrm{~mm}$. 


\subsection{Fatigue test}

Fatigue test have been conducted on a GUNT WP140.1 fatigue machine offering $0.37 \mathrm{~kW}$ of power and dynamic loads up to $300 \mathrm{~N}$. All fatigue tests were carried out at $\mathrm{R}=-1$ in room temperature. S-N curves have been obtained by starting from a stress level 1.03 to 1.04 times the upper yield strength of the material that is $66 \%$ of the ultimate stress. The respective value of the starting stress in both specimen conditions was $468 \mathrm{MPa}$. Then the stress has been decreased by increment of $30 \mathrm{MPa}$ a stress value until fracture of the specimens does not occur after 1 million cycles. Figure 4 shows fatigue test settlement.

\section{Results And Discussions}

\subsection{Effect of SDB on specimen roughness}

As expected, slide diamond burnishing has generated good surface roughness. Figure 5 illustrates the effect of slide diamond burnishing on the surface roughness of the fatigue specimens. The mean value roughness given in Fig. 5, corresponded to a series of 9 measurements on each specimen. Turning and grinding operations resulted in a surface roughness value of $0.450 \mu \mathrm{m}$, which is in good agreement with that recommended in literature [17]. Meanwhile slide diamond burnishing improved the surface roughness by compressing the external layer to a state of matt surface where a mean value of $0.12 \mu \mathrm{m}$ is obtained.

\subsection{Effect of SDB on specimen microhardness}

From the microhardness point of view, burnishing allows the surface layers to be consolidated by the phenomenon of work hardening, which is manifested by an increase in microhardness (Fig. 6). The value of microhardness on the outer layer of SDB surface, increased from $301 \mathrm{HV}_{3}$ to $535 \mathrm{HV}_{3}$ that is 1.77 times. An exploratory measurements of microhardness on the external layers of the SDB specimens revealed that have been subjected to hardening over $250 \mu \mathrm{m}$ depth from the outer layer. Figure 7 illustrates the hardening of the external layers expressed in terms of microhardness down to a depth of about $200 \mu \mathrm{m}$ by increment of 0.025 . The evolution of the surface hardening can be modeled through a trend following a power law, Equ (1).

$\mathrm{HV}=82.501 \times \mathrm{D}^{-0.596}$

$\mathrm{D}$ is the distance beneath the outer layer.

In fact, down to $100 \mu \mathrm{m}$, microhardness dropped to the value given by the turning and grinding process at the outer surface. When going deeper down to $200 \mu \mathrm{m}$, the microhardness continues to decrease until it becomes constant at a depth of $250 \mu \mathrm{m}$. Thence the SDB treatment generate a hardening process that performance the quality of the outer layer and reduces the detrimental effect of the turning and grinding process. Which is in good agreement with that recommended in literature [18].

\subsection{Effect of SDB on Wohler curves of AISI 52100 steel.}


Figure 8 illustrates the stress-strain curves of two types of specimens: the as machined (AM) and the slide diamond burnished (SDB). At least 3 fatigues tests at each level of applied stress have been reproduced at a stress ratio of $\mathrm{R}=-1$ in order to get best $\mathrm{SN}$ fitting curves. As the stress decreases from a stress value $3 \%$ above the upper yield strength of the material (568 MPa) by increment of $30 \mathrm{MPa}$, to a stress level of $308 \mathrm{MPa}$, the fatigue life increases slowly at first when fracture appears after 60000 cycles. Then the fatigue life increases quite rapidly as the applied stress level is decreased when a fatigue limit is observed after 1 million cycle for a stress level of $222 \mathrm{MPa}$ for the slide diamond burnished specimens and $190 \mathrm{MPa}$ for the as machined specimens. Reference tests have been left to end up to 10 million cycles without observing fracture. A mean value of the scatter in results is represented because the fatigue sensitivity to a number of test and material parameters are impossible to control.

From Fig. 8, it can be clearly seen that comparing to machined and grinded specimens; slide diamond burnishing has improved the fatigue life resistance of the material since the fatigue limit has increased from $190 \mathrm{MPa}$ to $222 \mathrm{MPa}$. In fact, hardening, generated by slide diamond burnishing, permitted to compress the external layers obtained after machining, grinding, and therefore reduced stress concentration zone. Figure 9 shows the fracture surface of both types of specimens. In the case of the slide diamond burnished specimen, the center rapid fracture zone is clearly defined from the propagation zone. In the case of turned and grinded specimens, it is very difficult to separate the fracture zone from the propagation zone. The corresponding engineering models for both types of specimens are respectively expressed by power laws of the form given in Equ (2) and Equ (3):

\section{$\sigma_{\mathrm{SDB}}=1057.4 \times N^{0.112}(2)$}

\section{$\sigma_{\mathrm{MG}}=1104.3 \times N^{0.127}(3)$}

\subsection{Effect of shoulder fillet radius on SN curves in AISI 52100 steel}

It is interesting to examine the behaviour of fatigue life at high stress levels where the value of applied stress is $75 \%$ above the material yield stress. The non-burnished specimens show lower life at all stress levels comparing to the slide burnished specimens. Thus SDB process improves the fatigue life and the improvement can be quantified by using equations (2) and (3). The results are in good agreement with those reported in literature $[13,14,19]$.

Figure 10 illustrate comparative SN curves plots with literature data [14] for similar materials. Basically, similar trend are observed however, the present results show lower fatigue life than those reported by Travieso for AISI 1038 material. In fact the decrease of the fatigue life is attributed to the radius of the specimen shoulder which smaller than that used by Travieso et al. They have used $4 \mathrm{~mm}$ ball burnishing tool where as in the present work, a $2.5 \mathrm{~mm}$ diameter diamond burnisher generated excessive stress concentration at the specimen shoulder. Therefore, even though that the slide diamond burnishing improves the surface roughness of the component, the fatigue life is very sensitive to shoulder radius. 


\section{Conclusion}

The present work is a contribution in determining the fatigue endurance of slide diamond burnishing on of AISI 52100 steel components. SDB process improved the roughness of the material to reach a value of $\mathrm{Ra}=0.12 \mu \mathrm{m}$ and generated hardening on $250 \mu \mathrm{m}$ deep outer surfaces of the components. The microhardness increased from 301 to $541 \mathrm{HV}_{3}$. Hardening generated a decrease of the microhardness down to $220 \mathrm{HV}_{3}$. The fatigue endurance represented $50 \%$ of the material yield stress for the SDB components and $40 \%$ for the non-burnished components. Thus SDB process improves the fatigue life. The improvement is quantified through engineering power law.

Results are in good agreement with those given in literature. In fact, a comparative analyses with SN curve of similar material AISI 1038 steel revealed similar trend behaviour. In addition, it permitted to sort out that fatigue life of cylindrical components are highly sensitive to the radius of the components shoulder radius.

\section{Declarations}

\section{Acknowledgements}

The authors would like to thank the staff of AMM of the Algerian steel company in El-Hadjar, Annaba, for the furniture of the material and the preparation of fatigue specimens. Thanks to URASM, the applied research unit in welding and metallurgy of Annaba, for analyzing the composition of the material; microhardness measurements, and metallographic observations. A great thank to S.Remili, metallurgical engineer at URASM for his important help.

\section{a. Funding}

The authors would like to thank the General Directorate of Scientific Research and Technological Development (DGRSDT, Algerian Minister of Higher Education and Scientific Research) for financial support. Project $\mathrm{N}^{\circ}$ A11N01UN230120200004

\section{b. Conflicts of interest/Competing interests}

This present work has been carried out during the last 3 years in order to meet an industrial need of the mechanical manufacturing company Ateliers Maghrébins de Mécanique in Annaba in Algeria, which concerns the study of the opportunity to improve the roughness surface of machined cylindrical parts by using burnishing operation. The company has supplied the material and prepared over 100 fatigue test pieces. A literature review has been oriented towards in order to identify the work carried out in this direction, particularly the work of Travieso-Rodriguez et al 2019 [14] and Hamadache H [15]. Slide diamond burnishing process has been carried out at the research laboratory of advanced technology in production engineering using a purpose design burnishing tool. Roughness and hardness measurements 
were necessary to better understand the Wöhler curves that were plotted. This work will be integrated into an industrial context.

c. Availability of data and material (data transparency): Not applicable

d. Code availability (software application or custom code): Not applicable

e. Ethics approval (include appropriate approvals or waivers): Not applicable

f. Consent to participate (include appropriate statements): Not applicable

g. Consent for publication (include appropriate statements) Not applicable

h. Authors' contributions:

Experimental work and data acquisition: Ouahiba Taamallah and Hamid Hamadache. Methodology:

Ouzine Boussaid, Hamid Hamadache. Literature review: shared by all authors. Discussions shared by all authors.

\section{References}

1. Maximov JT, Duncheva GV, Anchev AP, Dunchev VP, Capek J (2021) A cost-effective optimization approach for improving the fatigue strength of diamond-burnished steel components. Journal of the Brazilian Society of Mechanical Sciences Engineering. 33-43 https://doi.org/10.1007/s40430020-02723-6

2. Hamadache H, Amirat A, Chaoui K (2008) Effect of diamond ball burnishing on surface characteristics and fatigue strength of XC55 steel. Int Review Mech Eng 1:40-48.

DOl:https://doi.org/10.15866/irece.v6i6.8201

3. Lopez LN, Lamikiz A, Munoa J, Sanchez JA (2005) Quality improvement of ball-end milled sculptured surfaces by ball burnishing. Int J Mach Tools Manuf V 45:1659-1668. https://doi.org/10.1016/j.jimachtools.2005.03.007

4. Alberto S R, José A P A, Antonio J B G, Eduardo A G, Héctor P M, Noé S R (2017) The ball-burnishing process: state of the art of a developing technology. http://dx.doi.org/10.6036/7916.

5. Hamadache H, Taamallah O, Zemouri Z (2014) Characterization Layers Hardened Burnished Steel AISI/SAE 3115. International Journal of Mechanics Applications 4(1):13-19.

DOI:10.5923/j.mechanics.20140401.03

6. Yoshimasa T, Hiroyuki S (2018) Effect of Tip Shape of Frictional Stir Burnishing Tool on Processed Layer's Hardness, Residual Stress and Surface Roughness. Coatings 8-32 Doi:10.3390/coatings8010032

7. Maximov J T, Duncheva G V, Anchev A P, Ichkova M D (2019) Slide burnishing-review and prospects, The International Journal of Advanced Manufacturing Technology. https://doi.org/10.1007/s00170- 
019-03881-1

8. Rodríguez A, Lopez LN, Celaya A, Lamikiz A, Albizuri J (2012) Surface improvement of shafts by the deep ball-burnishing technique. Surf Coat Technol 206:2817-2824.

Doi:10.1016/j.surfcoat.2011.11.045

9. Chomienne V, Valiorgue F, Rech AJ, Verdu C (2016) Influence of ball burnishing on residual stress profile of a 15-5PH stainless steel. CIRP Journal of Manufacturing Science Technology 13:90-96. http://dx.doi.org/10.1016/j.cirpj.2015.12.003

10. Ramón JM, Gemma F, Joan JR, Jordi L, Travieso-Rodriguez JA (2021) Superficial Effects of Ball Burnishing on TRIP Steel AISI 301LN Sheets. Metals 11-82 https://doi.org/10.3390/met11010082

11. Garcia GAA, Giovanni GG, Jerez MR, Travieso-Rodriguez JA, Guillermo R (2017) Ball-burnishing effect on deep residual stress on AISI 1038 and AA2017-T4. Materials and Manufacturing Processes. http://dx.doi.org/10.1080/10426914.2017.1317351

12. Sadeler R, Akbulut M, Atasoy S (2013) Influence of mechanical ball burnishing surface treatment on fatigue behaviour of AISI 1045 steel. Kovove Materialy 51(1):31-35. DOI:10.4149/km_2013_1_31

13. Avilés R, Albizuri J, Rodriguez A, Lopez LN (2013) Influence of low-plasticity ball burnishing on the high-cycle fatigue strength of medium carbon AISI 1045 steel. International Journal of Fatigue 55:230-244. https://doi.org/10.1016/j.ijfatigue.2013.06.024

14. Travieso-Rodriguez JA, Jerez MR, Gómez GG, Llumà FJ, Casadesús FO, Madueno GM (2019) Hardening effect and fatigue behavior enhancement through ball burnishing on AISI 1038, Journal of materials research technology. https://doi.org/10.1016/j.jmrt.2019.09.032

15. Hamadache H, Bourebia M, Taamallah O, Laouar L (2019) Surface hardening of 36 NiCrMo6 steel by ball burnishing process. Materials Research Express. Doi:10.1088/2053-1591/ab3733

16. Çiçek A, Kıvak T, Ekici E (2015) Optimization of drilling parameters using Taguchi technique and response surface methodology (RSM) in drilling of AISI 304 steel with cryogenically treated HSS drills. J Intell Manuf 26(2):295-305. DOI:10.1007/s10845-013-0783-5

17. Toboła D, Kalisz J, Czechowski K, Wronska I, Machyniav Z (2020) Surface Treatment for Improving Selected Physical and Functional Properties of Tools and Machine Parts-A Review. Journal of Applied Materials Engineering 60(1):23-36. Doi:10.35995/jame60010003

18. Hamadache H, Zemouri Z, Laouar L, Dominiak S (2014) Improvement of surface conditions of $36 \mathrm{Cr}$ Ni Mo 6 steel by ball burnishing process. Journal of Mechanical Science and Technology 28 (4) 1491-1498. DOI 10.1007/s12206-014-0135-1

19. McClung R C A (2007) literature survey on the stability and significance of residual stresses during fatigue. Fatigue Fract Eng Mater Struct. 30(3):173-205. Doi: 10.1111/j.1460-2695.2007.01102.x

\section{Figures}


Procedure of Fatigue specimen preparation:

a)

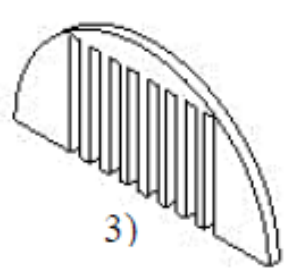

6)

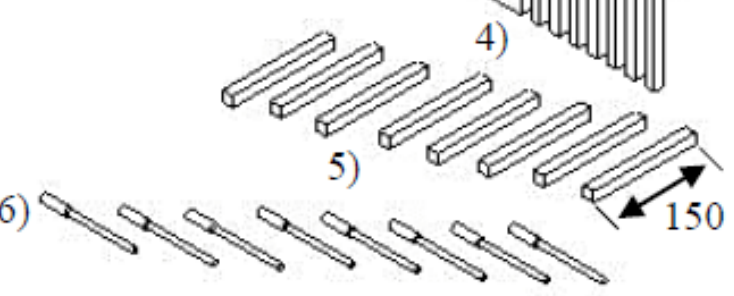

b)

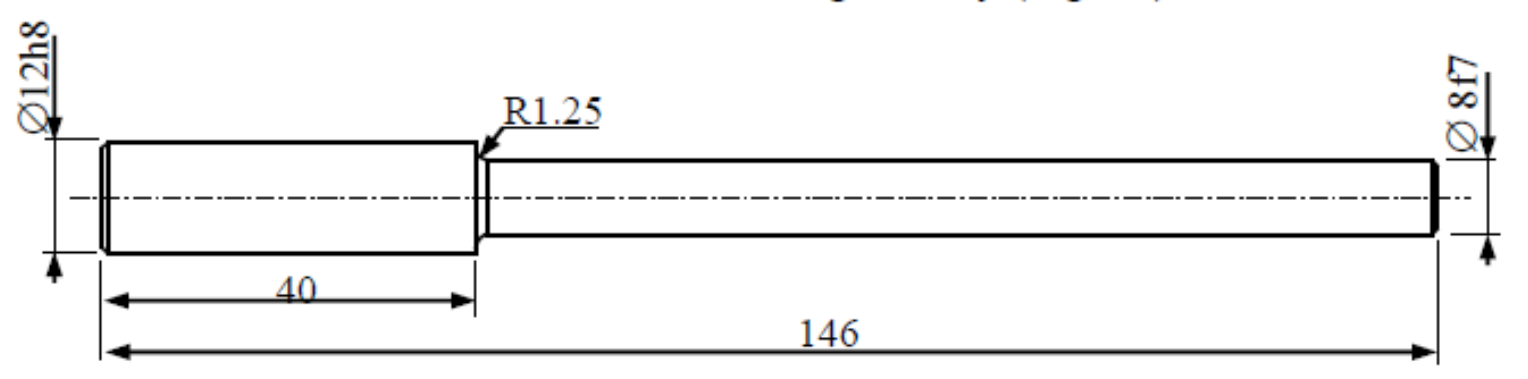

a) Saw Cut a $20 \mathrm{~mm}$ height cylinder from $400 \mathrm{~mm}$ diameter round parent bar

b) Saw Cut the cylinder into 2 halves

c) Extract from the two halves by milling $16 \mathrm{~mm}^{2} 16$ bars of $150 \mathrm{~mm}$ length

d) Lathe machining of the fatigue specimen according the desired geometry (Fig 1.b)

\section{Figure 1}

(a) Specimen preparation and (b) specimen geometry for fatigue tests. 


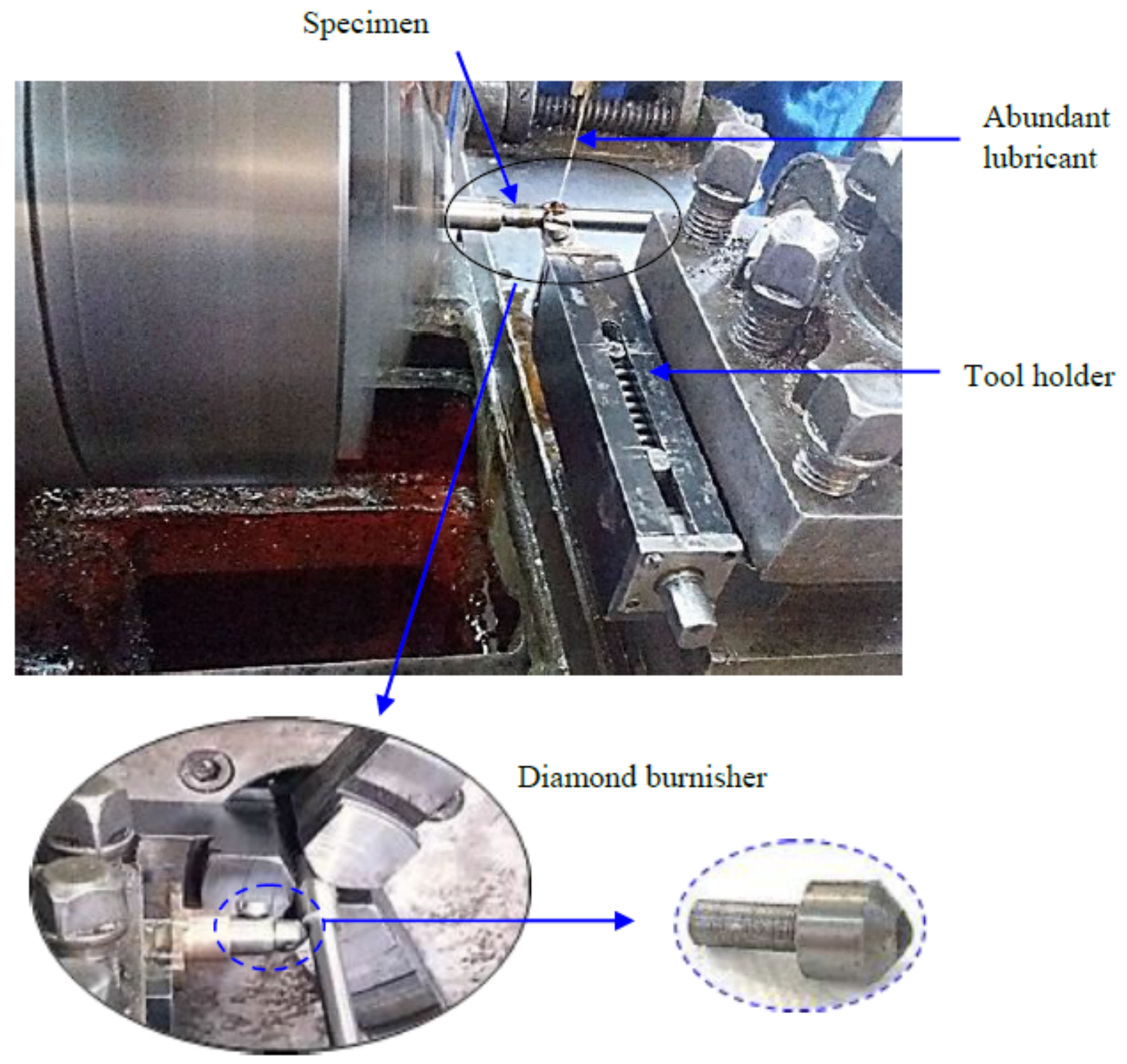

Figure 2

Slide diamond burnishing operation on 16k20 lathe. 


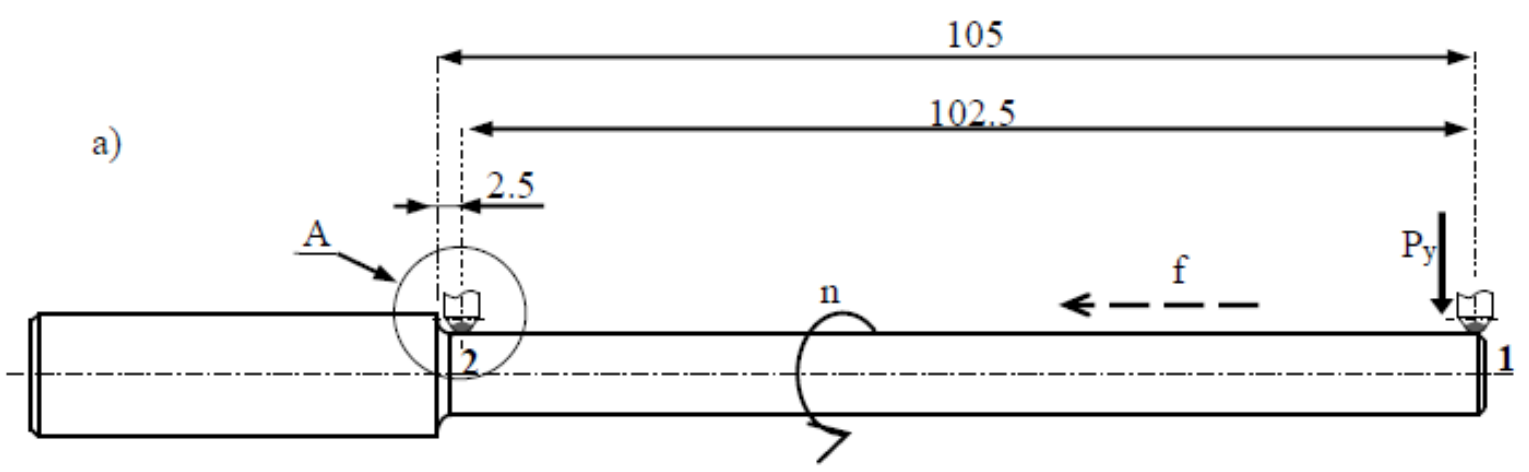

\section{$\underline{\text { Detail A }}$}

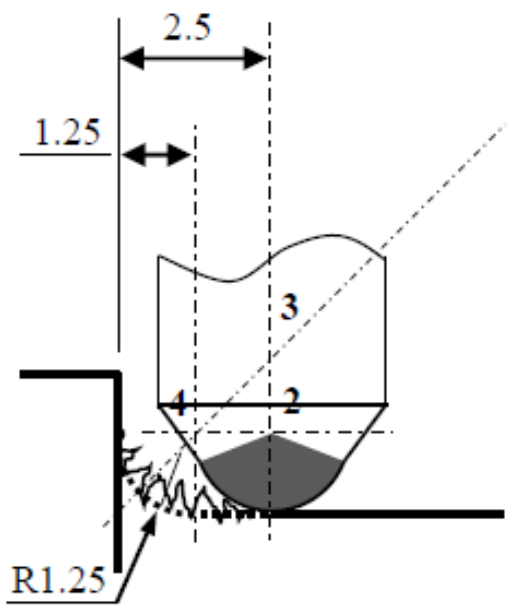

b)

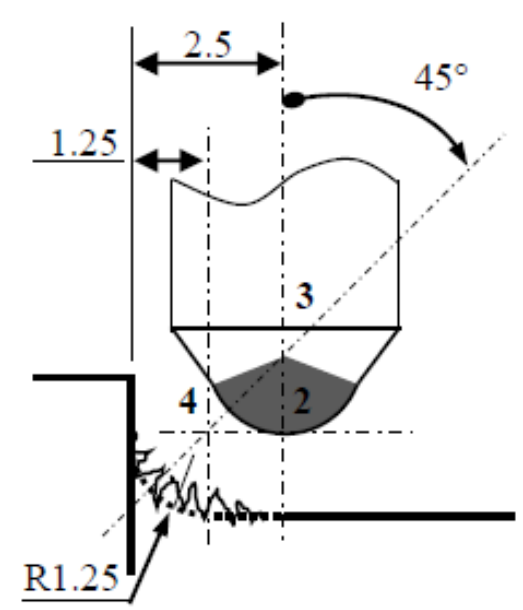

c)

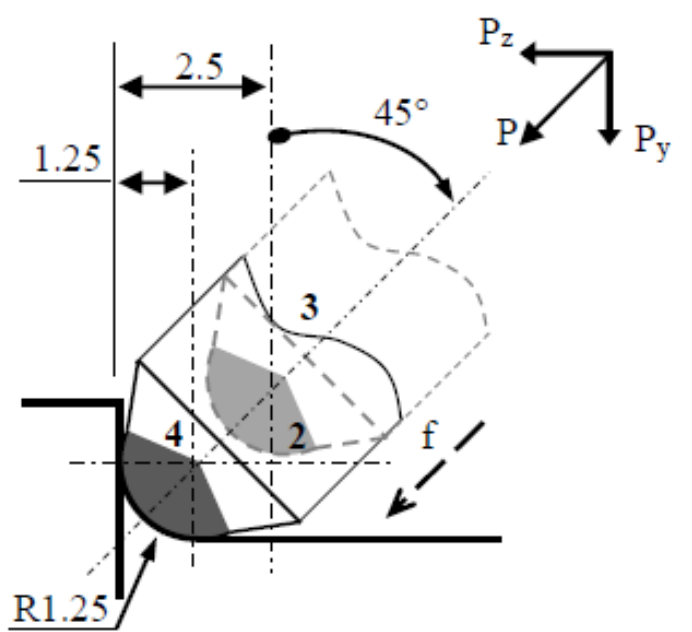

d)

\section{Figure 3}

Slide diamond burnishing operation cycles. 1) Cycle 1: Set the burnishing tool on point 1 with a radial pressure Py of $100 \mathrm{~N}$, while the specimen is rotating at $\mathrm{n}=560 \mathrm{rev} / \mathrm{min}$. Then Slide the diamond burnishing tool from point 1 to point 2 over a length of $102.5 \mathrm{~mm}$ (figure 3.a) with a feed rate 0.074 $\mathrm{mm} / \mathrm{rev}$. 2)Cycle 2: Remove the burnishing tool from point 2 to point 3 (Figure 3.c). 3)Cycle 3: Apply a rotation of $45^{\circ}$ and then set the burnishing tool on point 4 with a pressure of $\mathrm{P}$ of $100 \mathrm{~N}$, while the specimen is rotating. 4) Cycle 4: Remove the burnishing tool. 


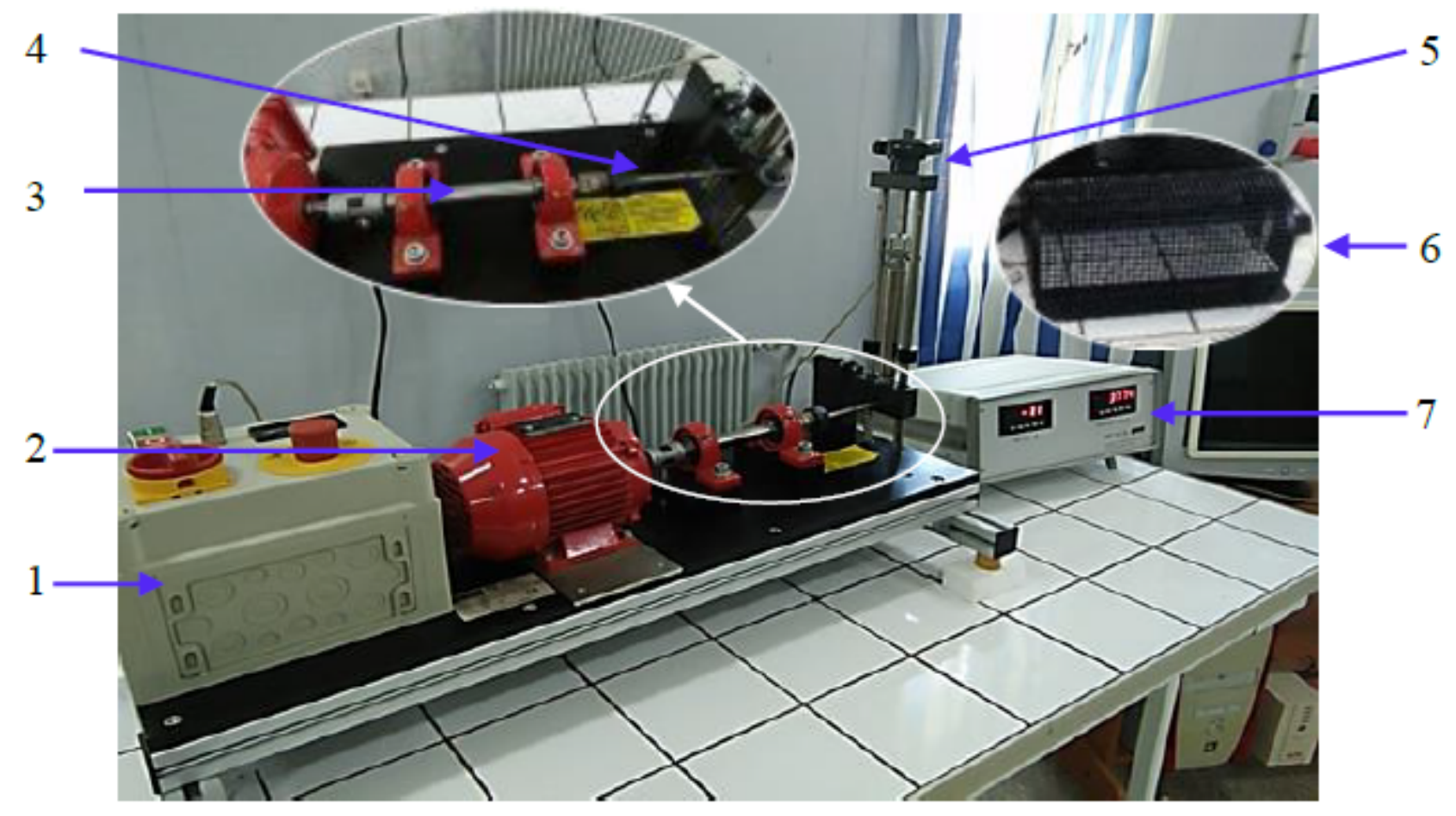

Figure 4

Fatigue testing machine fatigue testing machine Type GUNT WP 140.01: 1 switch box, 2 electric motor, 3 bearing, 4 clamped specimen, 5 load application device with spring balance and hand wheel, 6 protective cover, 7 measurement amplifier.

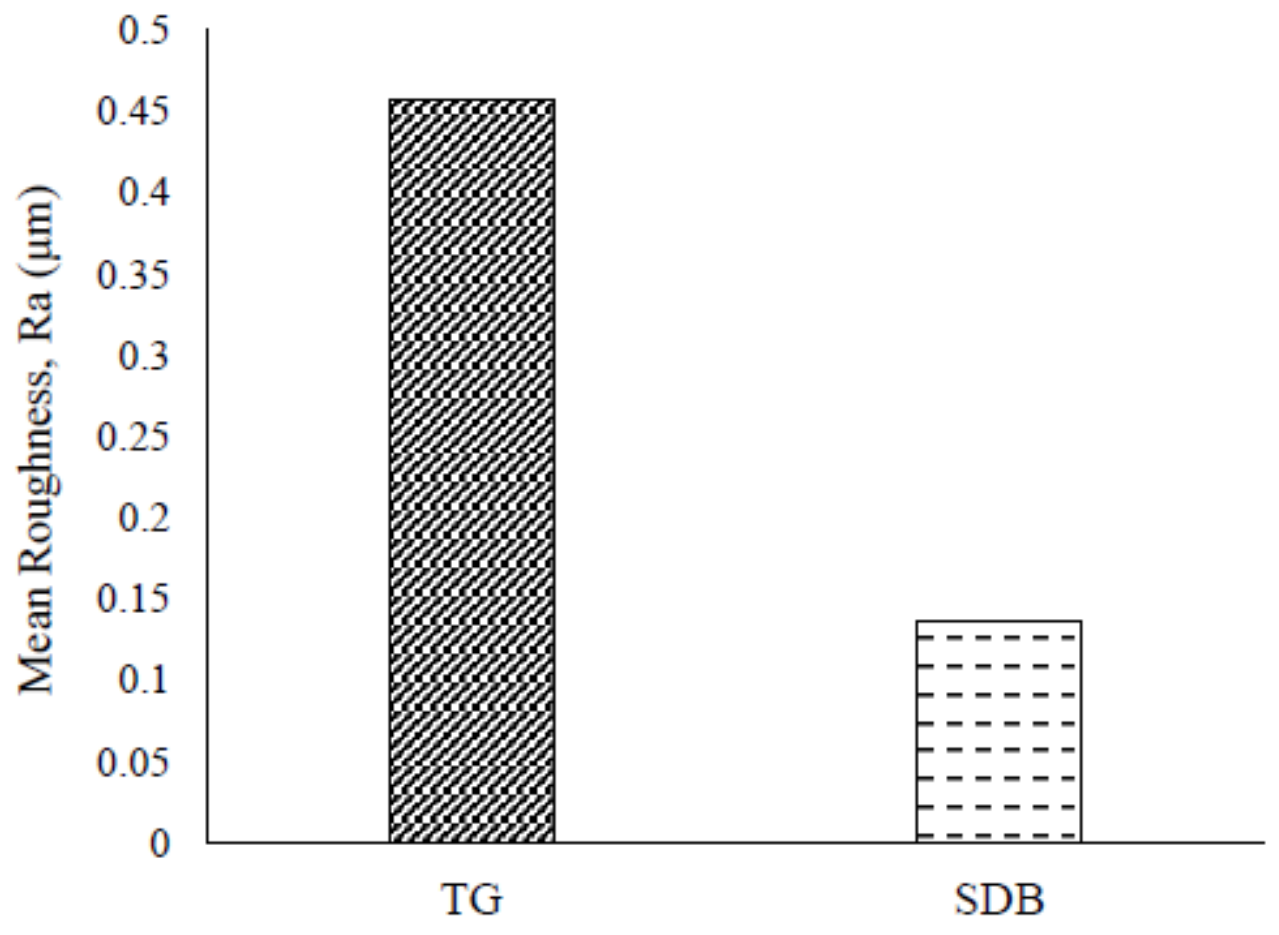

Type of specimen treatments

Figure 5 
Slide diamond burnishing effect on Roughness Ra. TG (turned and grinded specimens); SDB (Slide diamond Burnished Specimens).

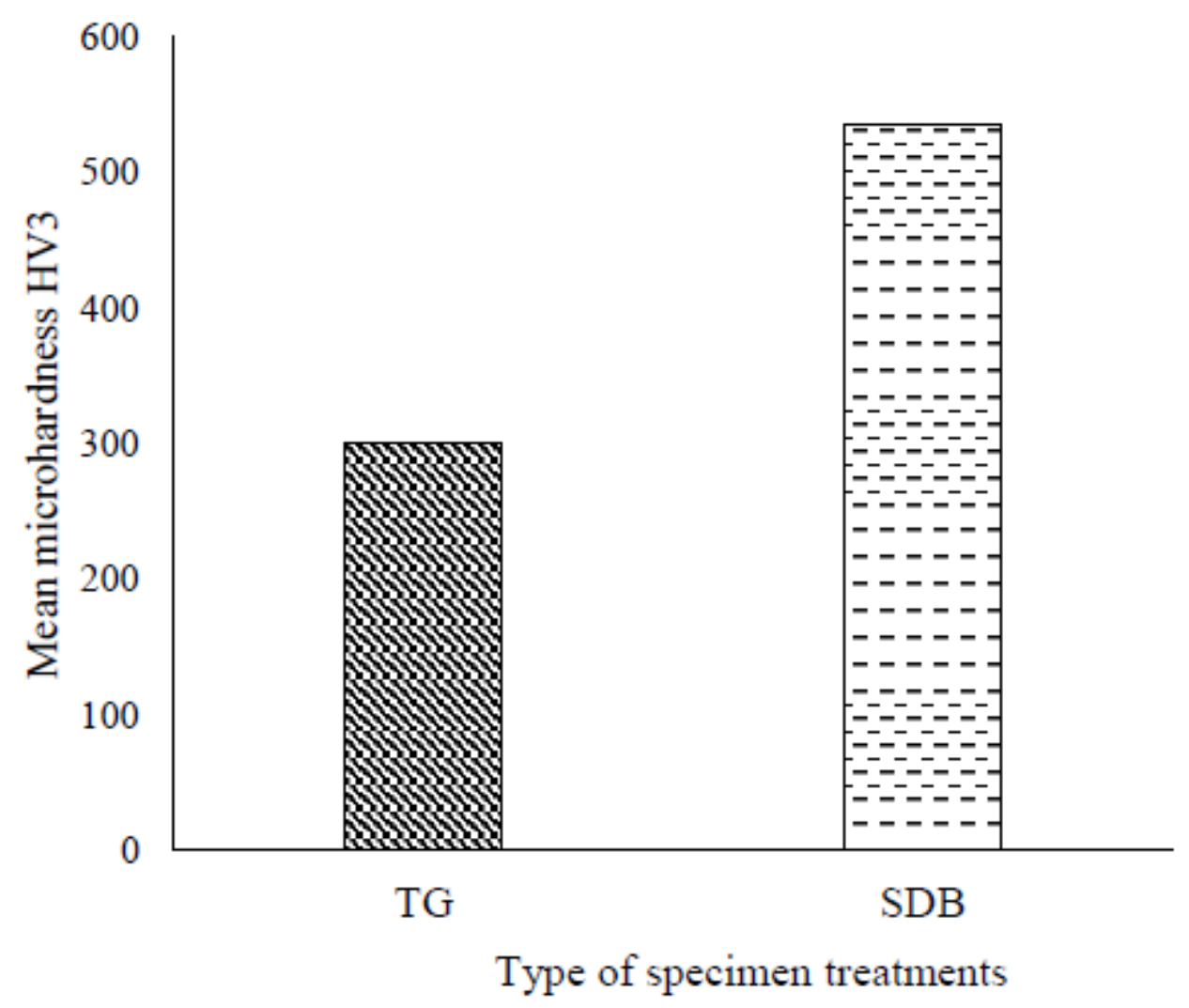

Figure 6

Slide diamond burnishing effect on HV microhardness. TG (turned and grinded specimens); SDB (Slide diamond Burnished Specimens). 


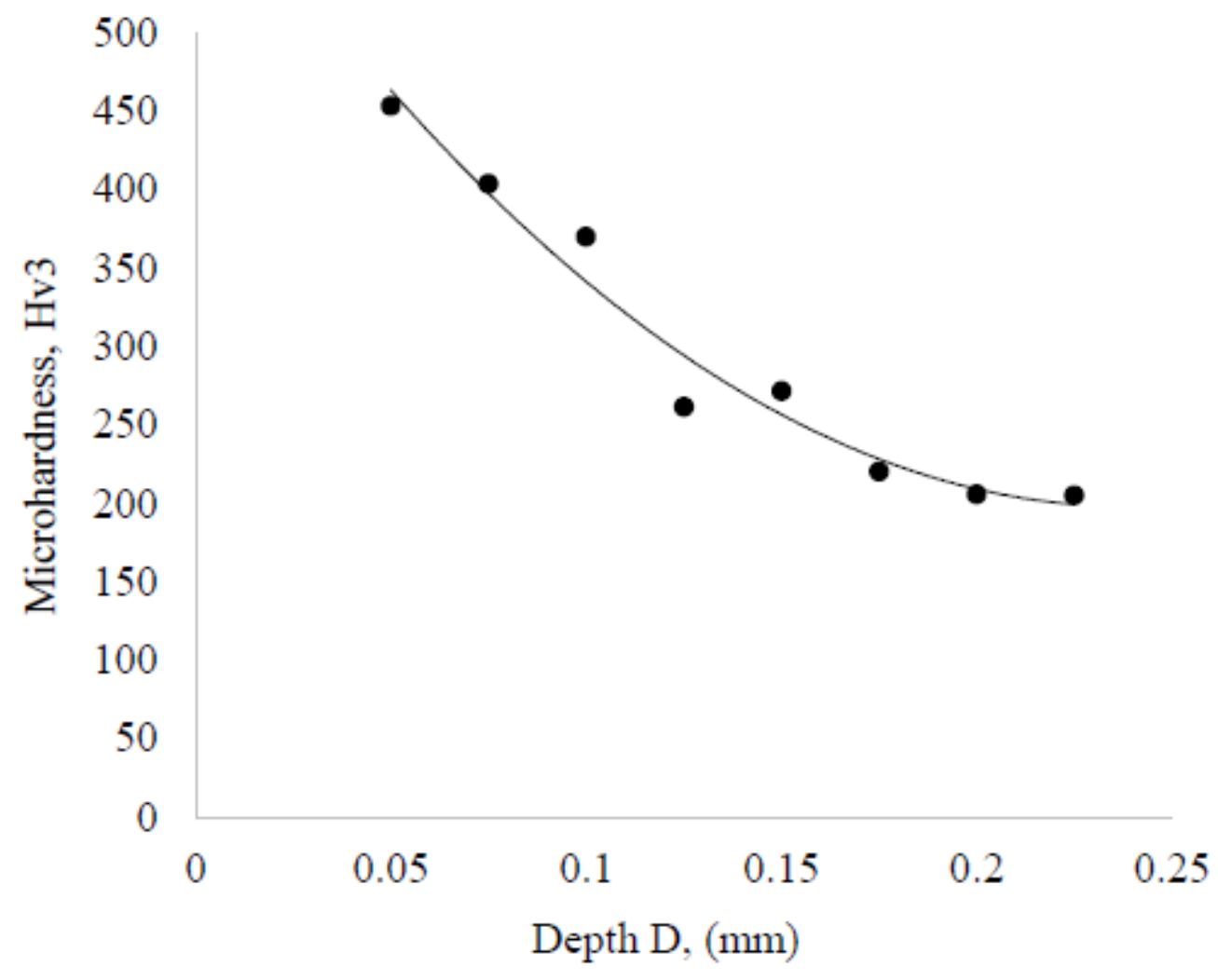

Figure 7

Hardening of the external layers of fatigue specimen through SDB.

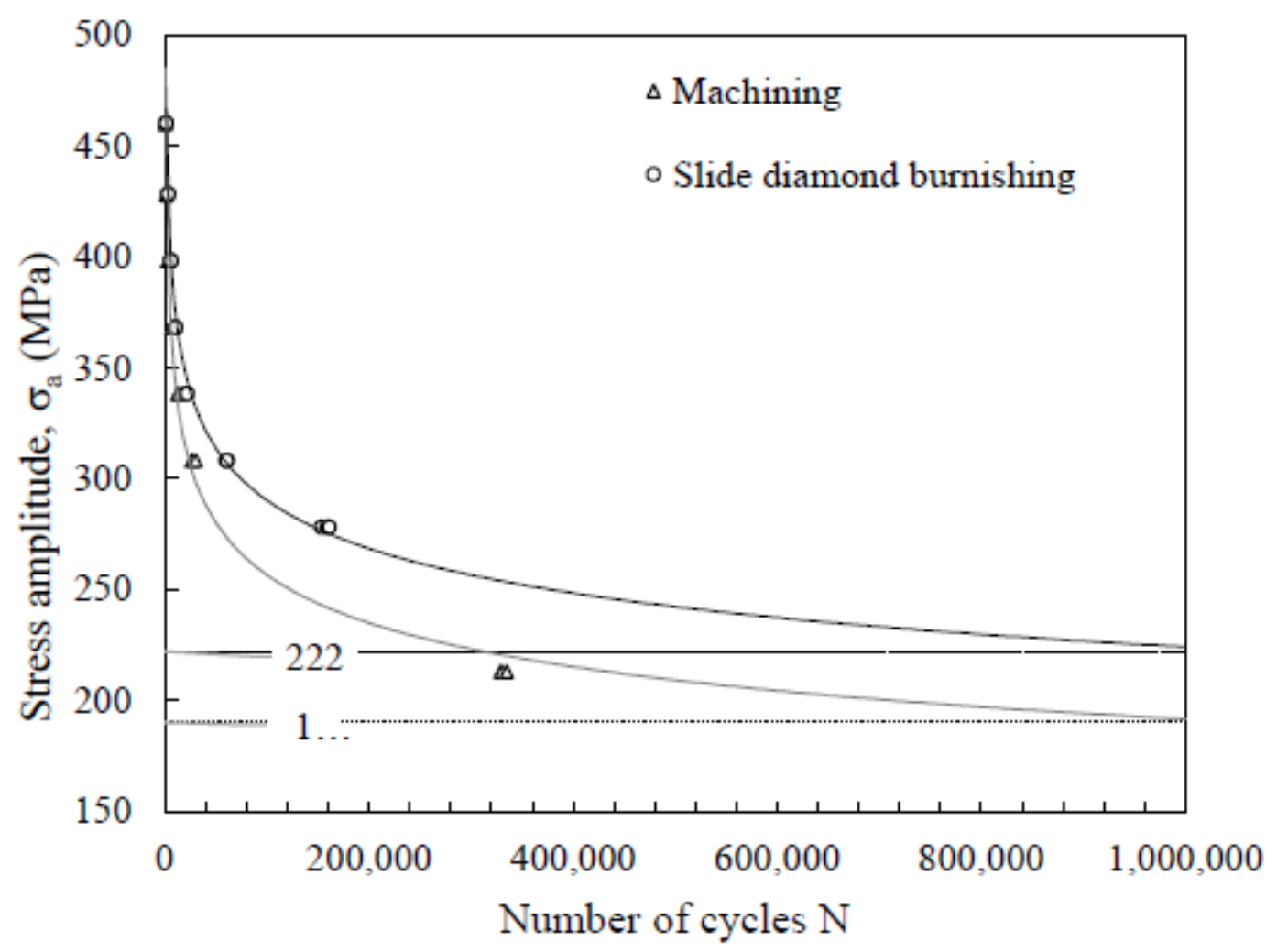

Figure 8 
SDB effect on the fatigue endurance of AISI5210 steel.

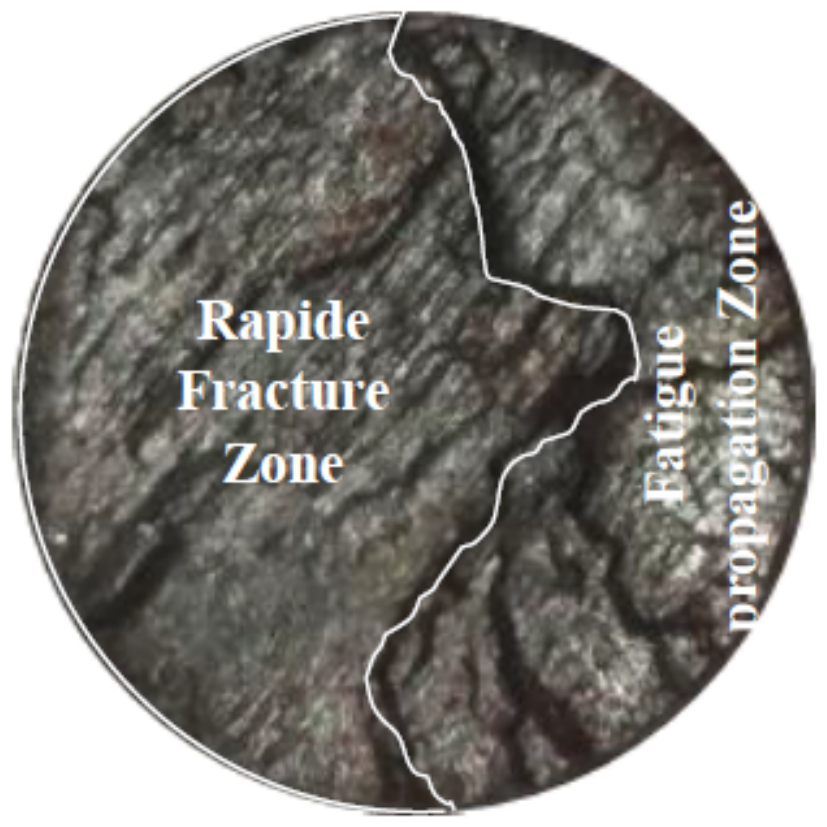

a)

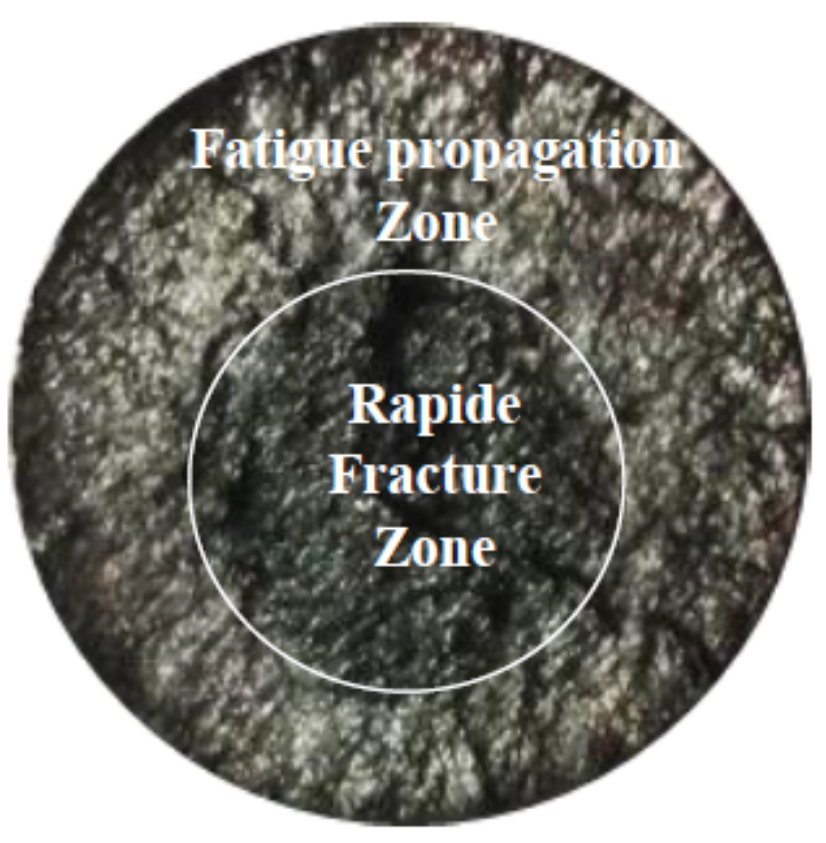

b)

Figure 9

Fatigue fracture surface of a) machined and grinded specimen and b) Slide diamond burnished specimen 


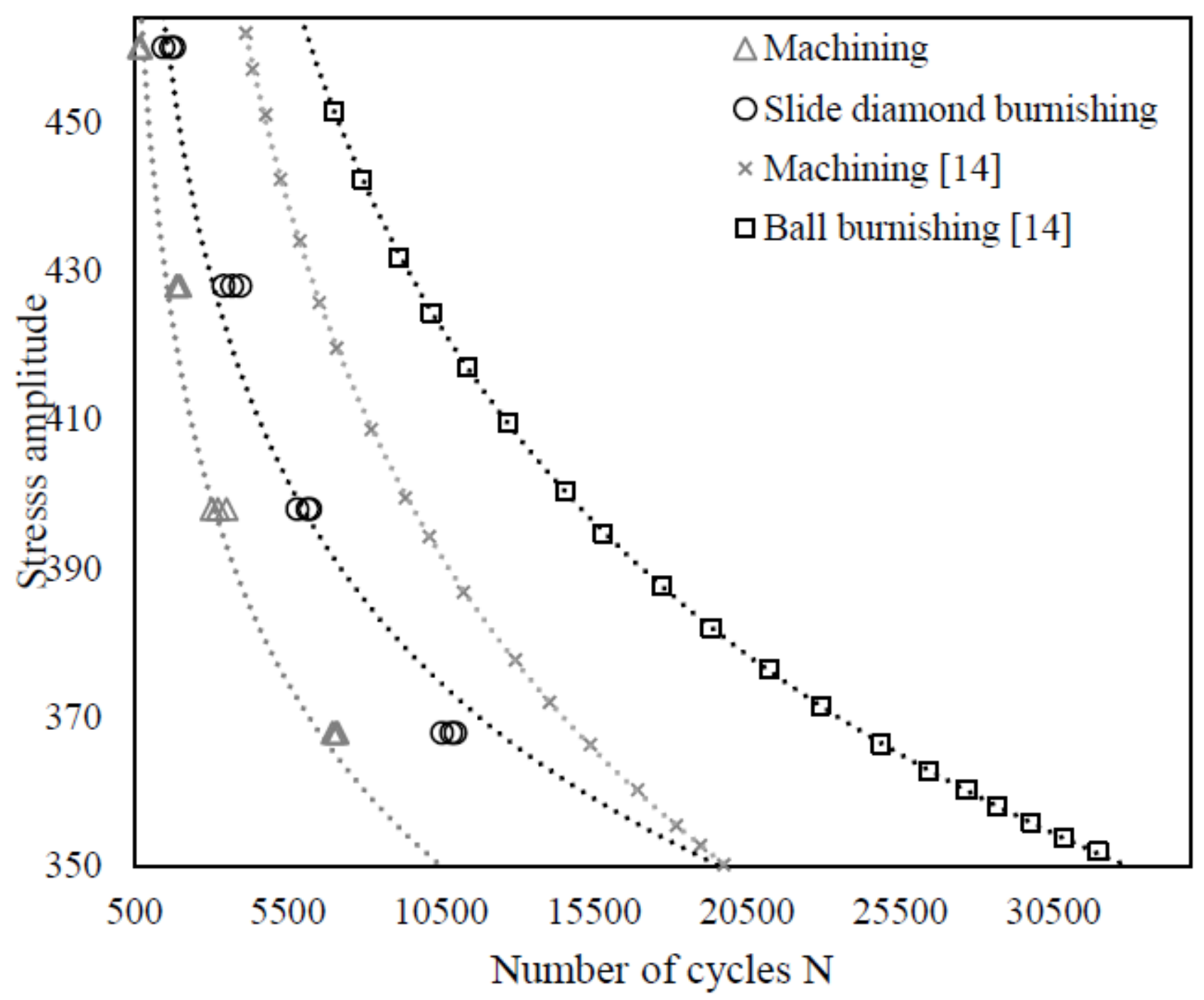

Figure 10

Shoulder fillet radius and SDB effect on early fatigue life of AISI 5210 steel. 